\section{JURNAL EKONOMI EFEKTIF}

ISSN : $2622-8882$, E-ISSN : 2622-9935

Jurnal Ekonomi Efektif, Vol. 3, No. 2, Januari 2021 @Prodi Manajemen Fakultas Ekonomi Universitas

Pamulang

\title{
PENGARUH KEPEMIMPINAN DAN MOTIVASI TERHADAP KINERJA KARYAWAN PT. FORTA LARESE JAKARTA PUSAT
}

\author{
Nur Lingga Setya Dewi \\ Universitas Pamulang, Tangerang Selatan, Banten, Indonesia \\ dosen02574@unpam.ac.id
}

Manuskrip: Sept-2020; Ditinjau: Okt-2020; Diterima: Okt-2020; Online: Jan-2021; Diterbitkan: Jan-2021

\begin{abstract}
ABSTRAK
Penelitian ini bertujuan untuk mengetahui pengaruh pengaruh kepemimpinan dan motivasi terhadap kinerja karyawan Metode yang digunakan adalah explanatory research dengan sampel sebanyak 116 responden. Teknik analisis menggunakan analisis statistik dengan pengujian regresi, korelasi, determinasi dan uji hipotesis. Hasil penelitian ini didapat, membuktikan adanya pengaruh positif dan signifikan antara motivasi terhadap kinerja karyawan. Dalam model persamaan regresi yang didapat adalah $\mathrm{y}=1,863+0,646 \mathrm{X} 1+$ $0,576 X 2$. Kemudian koefisien yang di dapat 0,893.
\end{abstract}

Kata Kunci: Kepemimpinan, Motivasi, Kinerja Karyawan.

\begin{abstract}
This study aims to determine the effect of leadership and motivation on employee performance. The method used is explanatory research with a sample of 116 respondents. The analysis technique uses statistical analysis with regression testing, correlation, determination and hypothesis testing. The results of this study were obtained, proving a positive and significant influence between motivation on employee performance. In the regression equation model obtained is $y=1.863+0.646 X 1+0.576 X 2$. Then the coefficient obtained is 0.893 .
\end{abstract}

Keywords: Leadership, Motivation, Employee Performance. 


\section{PENDAHULUAN}

\section{A. Latar Belakang Masalah}

Suatu perusahaan dalam melaksanakan kegiatannya, akan berusaha untuk mencapainya tujuan yang telah ditetapkan sebalumnya. Pada era globalisasi saat ini, faktor manusia merupakan masalah utama pada setiap kegiatan perusahaan. Perusahaan akan menghadapi berbagai tekanan yang akan menantang keahlian mereka dalam mengelola dan mengembangkan sumber daya manusia. Keberadaan sumber daya manusia sangat penting bagi perusahaan, karena merupakan kunci pokok yang menentukan keberhasilan pelaksanaasn kegiatan perusahaan. Dalam suatu perusahaan sumber daya manusia merupakan unsur yang sangat menentukan tercapainya tujuan dengan efektif dan efisien. Pada dasarnya setiap karyawan perusahaan akan mencurahkan dan daya serta pikirannya untuk meningkatkan kinerja yang sering disebut dengan istilah kinerja karyawan.

Kinerja karyawan (employee performance) adalah tingkat terhadap mana para karyawan mencapai persyaratan-persyaratanpekerjaan. Untuk meningkatkan kinerja, biasanya manajemen menggunakan teknik penilaian (appraisal).pada organisasi moden, penilaian memberikan mekanisme penting bagi manajemen untuk digunakan dalam menjelaskan tujuan-tujuan dan standar-standar kinerja dan untuk memotivasi kinerja individu dai waktu berikutnya.

Pentingnya motivasi kerja bagi suatu perusahaan yakni sebagai faktor pendorong karyawan. Faktor pendorong yaitu kebutuhan serta keinginan karyawan tersebut. Salah satu motivasi yang diberikan perusahaan adalah pemberian kompensasi yang sesuai dari kinerja yang dihasilkan dalam menyelesaikan tugas karyawan tersebut. Motivasi secara sederhana dapat dirumuskan sebagai kondisi ataupun tindakan yang mendorong seseorang untuk melakukan suatu pekerjaan atau kegiatan semaksimal mungkin karyawan untuk berbuat dan berproduksi. Peranan motivasi adalah untuk mengintensifkan hasrat dan keinginan tersebut, oleh karena itu dapat disimpulkan bahwa usaha peningkatan semangat kerja seseorang akan selalu terkait dengan usaha memotivasinya sehingga untuk mengadakan motivasi yang baik perlu mengetahui kebutuhan-kebutuhan manusia.

Semakin ketatnya tingkat persaingan bisnis mengakibatkan perusahaan dihadapkan pada tantangan untuk meningkatkan kinerja karyawan demi mempertahankan kelangsungan hidup perusahaan. Salah satunya PT Forta Laresee Jakarta. Perusahaan yang berada di Cideng Jakarta Pusat merupakan perusahaan sepatu khususnya sepatu safty. Peningkatan kinerja karyawan dan kesejahteraan para karyawan menjadi perhatian pihak manajemen PT Forta Laresee. Program-program yang diberikan oleh PT Forta Larese untuk meningkatkan kinerja karyawannya antara lain dengan memberikan motivasi kerja dalam bentuk pemberian insentif bagi karyawan yang memiliki kinerja yang baik. Dengan adanya pemberian motivasi melalui insentif, diharapkan karyawan akan berlomba-lomba untuk mendapatkannya dengan memberikan kinerja terbaik. Hal tersebut dilakukan untuk memicu peningkatan faktor-faktor pembentuk peningkaan kinerja.

Berdasarkan pemaparan di atas, penulis tertarik untuk melakukan penelitian dan pengkajian secara lebih mendalam terhadap masalah tersebut dengan judul penelitian, "Pengaruh Kepemimpinan dan Motivasi kerja Terhadap kinerja karyawan PT Forta Larese Jakarta Pusat". 


\section{B. Rumusan Masalah}

1. Apakah kepemempinan berpengaruh positif dan signifikan terhadap kinerja karyawan PT Forta Larese?

2. Apakah motivasi berpengaruh positif dan signifikan terhadap kinerja karyawan PT Forta Larese?

3. Apakah kepemimpinan dan motivasi berpengaruh positif dan signifikan terhadap kinerja karyawan PT Forta Larese?.

\section{Tujuan Penelitian}

1. Untuk mengetahui pengaruh kepemimpinan terhadap kinerja karyawan.

2. Untuk mengetahui pengaruh motivasi terhadap kinerja karyawan.

3. Untuk mengetahui pengaruh kepemimpinan dan motivasi terhadap kinerja karyawan.

\section{METODE PENELITIAN}

\section{Populasi}

Populasi dalam penelitian ini adalah semua karyawan PT FORTA LARESE sebanyak 116 orang

\section{Sampel}

Teknik pengambilan sampling dalam penelitian ini adalah samplel jenuh, dimana semua anggota populasi dijasikan sebagai sampel. Dengan demikian sampel dalam penelitian ini berjumlah 116 responden.

\section{Jenis Penelitian}

Jenis penelitian yang dipakai adalah asosiatif, dimana tujuannya adalah untuk mengetahui mencari keterhubungan antara variabel $\mathrm{x}$ dan variabel $\mathrm{y}$

\section{Metode Analisis Data}

Dalam menganalisis data digunakan uji instrumen, uji asumsi klasik, regresi, koefisien determinasi dan uji hipotesis.

\section{HASIL PENELITIAN DAN PEMBAHASAN}

\section{Analisis Deskriptif}

Pada pengujian ini digunakan untuk mengetahui skor minimum dan maksimum skor tertinggi, ratting score dan standar deviasi dari masing-masing variabel. Adapun hasilnya sebagai berikut:

Tabel 1. Hasil Analisis Descriptive Statistics

Coefficients ${ }^{a}$

\begin{tabular}{|c|c|c|c|c|c|c|c|c|}
\hline \multirow{2}{*}{\multicolumn{2}{|c|}{ Model }} & \multicolumn{2}{|c|}{ Unstandardized Coefficients } & \multirow{2}{*}{$\begin{array}{c}\begin{array}{c}\text { Standardized } \\
\text { Coefficients }\end{array} \\
\text { Beta }\end{array}$} & \multirow[b]{2}{*}{$\mathrm{t}$} & \multirow[b]{2}{*}{ Sig. } & \multicolumn{2}{|c|}{ Collinearity Statistics } \\
\hline & & B & Std. Error & & & & Tolerance & VIF \\
\hline \multirow[t]{2}{*}{1} & (Constant) & 22.255 & 3.249 & & 6.849 & .000 & & \\
\hline & $\mathrm{K}$ & .725 & .078 & .656 & 9.271 & .000 & 1.000 & 1.000 \\
\hline
\end{tabular}

a. Dependent Variable: KK

Kinerja Karyawan $=22,255+0,725 *$ Kepemimpinan. Pada persamaan tersebut dapat dilihat bahwa Kepemimpinan memiliki kemampuan untuk mempengaruhi kinerja karyawan pada PT Forta Larese Cideng Jakarta Pusat. Hal ini menunjukan bahwa kinerja karyawan pada PT Forta Larese Cideng Jakarta Pusat dapat dipengaruhi oleh kepemimpinan. 
Tabel 2

Coefficients $^{\text {a }}$

\begin{tabular}{|c|c|c|c|c|c|c|c|c|}
\hline \multirow[b]{2}{*}{ Mod } & & \multicolumn{2}{|c|}{ Unstandardized Coefficients } & \multirow{2}{*}{$\begin{array}{c}\begin{array}{c}\text { Standardized } \\
\text { Coefficients }\end{array} \\
\text { Beta }\end{array}$} & \multirow[b]{2}{*}{$t$} & \multirow[b]{2}{*}{ Sig. } & \multicolumn{2}{|c|}{ Collinearity Statistics } \\
\hline & & B & Std. Error & & & & Tolerance & VIF \\
\hline \multirow[t]{2}{*}{1} & (Constant) & 25.969 & 2.678 & & 9.696 & .000 & & \\
\hline & M & .640 & .065 & .679 & 9.869 & .000 & 1.000 & 1.000 \\
\hline
\end{tabular}

a. Dependent Variable: KK

Kinerja Karyawan $=25,969+0,640 *$ Motivasi. Pada persamaan tersebut dapat dilihat bahwa motivasi memiliki kemampuan untuk mempengaruhi kinerja karyawan pada PT Forta Larese Cideng Jakarta Pusat. Hal ini menunjukan bahwa kinerja karyawan pada PT Forta Larese Cideng Jakarta Pusat dapat dipengaruhi oleh kepemimpinan.

Tabel 3

Coefficients ${ }^{a}$

\begin{tabular}{|c|c|c|c|c|c|c|c|c|}
\hline \multirow[b]{2}{*}{ Mod } & & \multicolumn{2}{|c|}{ Unstandardized Coefficients } & \multirow{2}{*}{$\begin{array}{c}\text { Standardized } \\
\text { Coefficients }\end{array}$} & \multirow[b]{2}{*}{ t } & \multirow[b]{2}{*}{ Sig. } & \multicolumn{2}{|c|}{ Collinearity Statistics } \\
\hline & & B & Std. Error & & & & Tolerance & VIF \\
\hline \multirow[t]{3}{*}{1} & (Constant) & 1.863 & 2.411 & & .773 & .441 & & \\
\hline & $\mathrm{K}$ & .646 & .047 & .584 & 13.705 & .000 & .986 & 1.014 \\
\hline & M & .576 & .040 & .610 & 14.320 & .000 & .986 & 1.014 \\
\hline
\end{tabular}

a. Dependent Variable: KK

Berdasarkan tabel di atas dapat disimpulkan bahwa secara parsial Kepemimpinan dan Motivasi memiliki pengaruh positif dan signifikan terhadap Kinerja Karyawan karena memiliki nilai thitung yang lebih besar dari ttabel dan memiliki nilai significance di bawah tingkat kesalahan (alpha) sebesar 0,05.

Persamaan regresi yang dapat dibentuk adalah sebagai berikut:

Kinerja Karyawan $=1,863+0,646 *$ Kepemimpinan $+0,576 *$ Motivasi. Motivasi diperoleh varians minimum sebesar 28 dan varians maximum 44 dengan ratting score sebesar 3,40 dengan standar deviasi 4,016. Skor ini termasuk pada rentang sakala 3,40 4,19 dengan kriteria baik atau setuju.

Kinerja karyawan diperoleh varians minimum sebesar 29 dan varians maximum 49 dengan ratting score sebesar 3,81 dengan standar deviasi 4,183. Skor ini termasuk pada rentang sakala 3,40 - 4,19 dengan kriteria baik atau setuju.

\section{Analisis Verifikatif.}

\section{a. Uji Hipotesis}

Pengujian hipotesis dengan uji t digunakan untuk mengetahui hipotesis mana yang diterima.

Rumusan hipotesis: Terdapat pengaruh yang signifikan antara motivasi terhadap kinerja karyawan.

Tabel 4. Hasil Uji Hipotesis Motivasi Terhadap Kinerja Karyawan.

Coefficients a

\begin{tabular}{|c|c|c|c|c|c|c|c|c|}
\hline \multirow{2}{*}{\multicolumn{2}{|c|}{ Model }} & \multicolumn{2}{|c|}{ Unstandardized Coefficients } & \multirow{2}{*}{$\begin{array}{c}\begin{array}{c}\text { Standardized } \\
\text { Coefficients }\end{array} \\
\text { Beta }\end{array}$} & \multirow[b]{2}{*}{$\mathrm{t}$} & \multirow[b]{2}{*}{ Sig. } & \multicolumn{2}{|c|}{ Collinearity Statistics } \\
\hline & & B & Std. Error & & & & Tolerance & VIF \\
\hline \multirow[t]{2}{*}{1} & (Constant) & 25.969 & 2.678 & & 9.696 & .000 & & \\
\hline & $\mathrm{M}$ & .640 & .065 & .679 & 9.869 & .000 & 1.000 & 1.000 \\
\hline
\end{tabular}

a. Dependent Variable: KK

Dalam tabel di atas terdapat pengaruh dan signifikan antara Motivasi terhadap 
Kinerja Karyawan dengan kata lain Ho2 ditolak dan Ha2 diterima. Karena memiliki nilai probabilita atau nilai signifikan lebih kecil dari alpha sebesar 0,05 dan nilai thitung lebih besar dari ttable atau $(9,869>1,981)$.

\section{PEMBAHASAN HASIL PENELITIAN}

\section{Kondisi Jawaban Responden Variabel Motivasi}

Berdasarkan jawaban responden, variabel motivasi diperoleh ratting score sebesar 3,40 berada di rentang skala 3,40 - 4,19 dengan kriteria baik atau setuju.

\section{Kondisi Jawaban Responden Variabel Kinerja Karyawan}

Berdasarkan jawaban responden, variabel kinerja karyawan diperoleh ratting score sebesar 3,81 berada di rentang skala 3,40-4,19 dengan kriteria baik atau setuju.

\section{Pengaruh Motivasi Terhadap Kinerja Karyawan}

nilai korelasi (R) sebesar 0,893 yang berarti terdapat korelasi/hubungan yang sangat kuat antara variabel bebas yang terdiri dari Kepemimpinan dan Motivasi secara bersama-sama dengan variabel dependennya yakni Kinerja Karyawan. Besarnya adjusted coeficient of determination (Adjusted R2) sebesar 0,794 atau 79,4\% yang berarti variabel bebas yang terdiri dari Kepemimpinan dan Motivasi dapat memberikan kontribusi pengaruh sebesar $79,4 \%$ kepada Kinerja Karyawan sedangkan sisanya $(100 \%-79,4 \%)$ dapat diterangkan oleh faktor lain yang tidak dimasukkan ke dalam model.

\section{V.PENUTUP}

\section{Kesimpulan}

a. Pengaruh kepemimpinan terhadap kinerja. Dari hasil yang didapat, membuktikan adanya pengaruh positif dan signifikan antara kepemimpinan terhadap kinerja karyawan. Dalam model persamaan regresi yang didapat adalah $\mathrm{Y}=22,255+$ $0,725^{*}$ Kepemimpinan. Koefisien yang didapat sebesar 0,656. Kemudian Nilai thitung lebih besar dari ttable atau $(9.271>1,981)$

b. Pengaruh motivasi terhadap kinerja. Dari hasil yang didapat, membuktikan adanya pengaruh positif dan signifikan antara motivasi terhadap kinerja karyawan. Dalam model persamaan regresi yang didapat adalah y $=25,969+0,640 *$ Motivasi. Koefisien yang di dapat 0,679. Kemudian Nilai thitung lebih besar dari ttable atau $(9,869>$ 1,981)

c. Pengaruh kepemimpinan dan motivasi terhadap kinerja karyawan. Dari hasil yang didapat, membuktikan adanya pengaruh positif dan signifikan antara motivasi terhadap kinerja karyawan. Dalam model persamaan regresi yang didapat adalah $\mathrm{y}=$ $1,863+0,646^{*}$ Kepemimpinan $+0,576^{*}$ Motivasi. Kemudian koefisien yang di dapat 0,893

\section{Saran}

a. Kepemimpinan ternyata berkontribusi positif dan signifikan terhadap kinerja karyawan. Hendaknya keadaan ini perlu dipertahankan bahkan kalau bisa ditingkatkan dengan menekankan pada peningkatkan kemampuan dalam memberikan ide yang baik sehingga dapat meningkatkan hasil kinerja.

b. Pemimpin agar lebih memotivasi karyawannya agar meningkatkan kinerja karyawan

c. Pemimpin perlu secara insentif melalukan evaluasi terhadap motivasi karyawan sehingga dapat terus terjaga kualitasnya. 


\section{DAFTAR PUSTAKA}

Agus Subardi. Manajemen Pengantar Edisi Revisi. Yogyakarta: UPP AMP YKPN. 2001

Amin, Kunaefi Elfachmi. Evaluasi Kinerja Karyawan. Malang: LTSM, 2015.

Amirullah. Pengantar Manajemen. Jakarta: Mitra Wacana Media, 2015.

Arikunto, Suharsimi. Prosedur Penelitian Suatu Pendekatan Praktik. Jakarta, Rhineka Cipta, 2011

Cushway, Barry. Human Resource Management. PT. Elex Media Computindo: 2002

D Sunarsi. (2020). Kepemimpinan Bisnis Strategik. Kota Serang: Desanta Muliavisitama

Dessler, Garry. Manajemen Sumber Daya Manusia. Jakarta: Indeks, 2014.

Ghozali, Imam. Aplikasi Analisis Multi Variat Dengan Program SPSS. Semarang: BP Universitas Diponogoro, 2005

Kartono, Kartini. Pemimpin Dan Kepemimpinan. Jakarta: PT. Raja Grafindo Persada, 2008

Khoiri, A., Kahar, M. S., \& Indrawati, R. T. (2018, November). Ethnoscience Approach in Cooperative Academic Education Programs (COOP). In Journal of Physics: Conference Series (Vol. 1114, No. 1).

Khoiri, A., Nasihah, U., \& Kahar, M. S. (2017). Analisis prestasi belajar fisika berpendekatan SETS di tinjau dari motivasi berprestasi. Jurnal Riset dan Kajian Pendidikan Fisika, 4(2), 83-89.

Panggabean, Mutiara S. Manajemen Sumber Daya Manusia. Bogor: Ghalia Indonesia, 2004

Rivai, Viethzal dan Ahmad Fawzi. Manajemen Sumber Daya Manusia Untuk Perusahaan, Jakarta: Raja Grafindo Persada, 2009

Sarwani, S., Akbar, I. R., Handoko, A. L., \& Ilham, D. (2020). Pengaruh Pelatihan dan Motivasi terhadap Produktivitas Kerja Karyawan pada PT. Lion Mentari Airlines Bandara Internasional Soekarno Hatta Cengkareng. Jurnal Ilmu Komputer dan Bisnis, 11(2a), 91-100.

Sedarmayanti. Manajemen Sumber Daya Manusia, Bandung: Refika Aditama, 2013

Sofyan, S., Prasada, D., \& Akbar, I. R. (2020). Pengaruh Motivasi, Lingkungan Kerja dan Kepuasan Kerja Terhadap Kinerja Guru SMP/MTs Muhammadiyah Cabang Sawangan

Sunarsi, D. (2018). Pengaruh Gaya Kepemimpinan dan Disiplin Kerja Terhadap Kinerja Karyawan Pada CV. Usaha Mandiri Jakarta. JENIUS (Jurnal Ilmiah Manajemen Sumber Daya Manusia), 1(2).

, Winata, H., Gunartin, G., \& Paeno, P. (2020). Analisis Gaya Kepemimpinan Kepala Desa Dalam Pengembangan Desa Cidokom Gunung Sindur Kabupaten Bogor. Jurnal Ekonomi Efektif, 2(3).

Surya Dharma. Manajemen Kinerja : Falsafat Teori dan Penerapannya. Yogyakarta: Pustaka Pelajar, 2012

Sutrisno, Edy. Manajemen Sumber Daya Manusia (cetakan ke Tujuh). Jakarta: Kencana Prenada Media Group, 2015

Timpe, A., Dale. Kinerja, Jakarta: Gramedia Utama, 2009

Wibowo. Manajemen Kinerja. Jakarta: Raja Grafindo Persada. 2016

Wirawan, Ahmad. Kinerja Bebasis Kompetensi, Jakarta: Ghalia Indonesia, 2013

Wirawan. Kepemimpinan: Teori, Psikologi, Perilaku Organisasi, Aplikasi dan Penelitian. Jakarta: PT. Raja Grafindo Persada. 2013

Yani, M. Manajemen Sumber Daya Manusia. Jakarta: Mitra Wacana Media. 2012. 